\title{
Suggestions, Methods and Examples of Monitoring of Rock Structures and Excavation of Rock Mass
}

\author{
Evandro Moraes da Gama \\ UFMG, Belo Horizonte, Minas Gerais, Brazil \\ Email: evandrodagama@gmail.com
}

How to cite this paper: da Gama, E.M. (2020) Suggestions, Methods and Examples of Monitoring of Rock Structures and Excavation of Rock Mass. Geomaterials, 10, 91-104.

https://doi.org/10.4236/gm.2020.104006

Received: June 19, 2020

Accepted: August 11, 2020

Published: August 14, 2020

Copyright $\odot 2020$ by author(s) and Scientific Research Publishing Inc. This work is licensed under the Creative Commons Attribution International License (CC BY 4.0).

http://creativecommons.org/licenses/by/4.0/

\section{(c) (i) Open Access}

\begin{abstract}
Rock mechanics projects, excavations and rock mass monitoring are day-by-day concerns of professionals and scientists of rock engineer. Technological advances observed in the 20 and 21 centuries provided high precision equipment capable of establishing deformation and estimating the rock mass stress remotely and in real time. In addition, in order to confirm and study the data obtained with theses equipment, numerical programs of modeling became more accessible to schools, research centers and private companies. Monitoring an excavation requires, besides understanding fully the rock structure, precise definitions and goals: why, how, where. This article discusses concepts of monitoring, modeling and calibration, as well as presents examples of applications where these questions were successfully answered.
\end{abstract}

\section{Keywords}

Monitoring, Monitored Excavations, Calibrated Model, Rock Structure, Rock Mass

\section{Introduction}

The main objectives of excavations monitoring are to gather the deformation data and to estimate the state of stress "in situ" and "over time" that will enable to understand the geomechanic rock mass behavior. Therefore, the monitoring process should allow the investigators:

- To evaluate the excavations safety;

- To confirm the premises assumed in the project;

- To analyze and understand the rock mass mechanical behavior and its failure phenomenon; 
- To gather "in situ" and more reliable data for the project;

- To provide data for numerical model calibration;

- To confirm premises used in the excavation process;

- To control the quality of data obtained;

- To provide data for modifying and improving the project;

- To evaluate the effect of corrective measures and variations in the excavation methodology.

The possibility of a rock mass failure around excavations cannot be eliminated or accessed with high accuracy. However, monitoring procedures provide ways to reduce these risks to acceptable levels. "In situ" data are the most reliable information since they are not subjected to project simplifications or laboratory analysis. The scale effect and the unpredictable geological complexities are not neglected but are, naturally, taking into account [1]. However, instrumentation and monitoring any excavation require not only a wide knowledge about the rock mass itself, but also to decide why, when, how, where, and, what should be monitored. The continuous advances in the computer science such as the processing speed and storage capacity of microcomputers allow more and more the application of theoretically well-known mathematical methodologies, in solving geomechanic problems. Today, programs using the method of finite elements [2], finite differences [3], boundary elements [4] and discrete elements [5] [6] are relatively easy to implement in most microcomputers available in the market. In addition, new improvements in the numerical methodologies were made available since the application of the theory of continuous equivalent [6] bringing up the possibility of simulating larger displacements and even the collapse of systems. In the field of rock mass instrumentation, several pieces of equipment were developed to evaluate virgin stress state like the [7] Hydraulic Fracture Equipment and the LANDIS system, which uses laser beams to measure displacements [8]. One can say that each geomechanic field has developed, somehow, independently, and not many researchers have dedicated their efforts to integrate numerical modeling and rock mass instrumentation. [9] was one of the first to present a methodology that combined the instrumentation to numerical simulation (SPDR) using data obtained in real time. [10] discusses the wide use of numerical modeling methodologies. However, he points out that the prediction of the mechanical behavior depends heavily on the reliability of data used. [8] shows a methodology where the rock mass instrumentation and the boundary element numerical modeling are applied in the induced stress and displacements monitoring in an underground gold mine. It is very complex to accurately quantify geological structures, as well as geomechanic properties such as stress state, water level and pressure, permeability, plastic and elastic parameters, fluidity and resistance of a rock mass. To overcome these difficulties, the auscultation together with a numerical analysis is highly effective during and after the excavation procedures, in order to monitor the stability of the structures, and to re-evaluate the geological and geomechanical parameters used in the analysis. It would reduce the differences between the expected and the actual behaviors al- 
lowing the investigator to design structures holding safety factors more reliable, avoiding, in many cases, the application of multipliers to the safety coefficients. Stress and strain measurements have been done, for many years, with the help of gauges that are read visually by an operator. This kind of instrumentation is, invariably, not directly connected to any system of analyses. In addition, the data are not gathered continuously over time. Moreover, their installation is time consuming and it can only be installed in places with relative stability. Therefore, they cannot be used in places of greater interests of study. This article depicts the monitoring procedures using a Monitoring System of underground excavation (Sismo), [11] and the calibrated modeling of an underground Shrinkage Stoping Zinc mine. The instrumentation made it possible to study the effect of blasting in small galleries and to predict the rupture of small pillars. A numerical model was built with the software UDEC (Universal Distinct Element Code - Itasca Consulting Groupe) version 3.0. The model was used to study the effect of distressing and the related deformations around an underground opening excavated with drilling and blasting.

\section{Monitoring Rupture Processes}

The main objective of a monitoring system [12] is to acquire data, by measuring deformations (strain) and estimating stress, that can be used in order to accurately understand the rock mass geomechanic behavior. [13] showed the advantages of monitoring based upon the convergence and confining method. [14] showed that normal stresses vary rapidly close to excavating surfaces while tangential stresses vary gradually. He also showed that the shear stress may Variation directions close to the excavation walls. Back-analysis, in its simplest way can be understood as the reversed process of the ordinary analysis, which means, to introduce known values of forces, stresses, displacements and strain into a model to obtain the material's mechanical parameters. That emphasizes the importance of a good system of monitoring when back-calculation is used. When the material's parameters are obtained, the model may be used to design, geometry and size, of future excavations and to propose better methodologies of excavations [15]. This kind of investigation allows using a statistical distribution of the data back analyzed. Controlled modeling objectives, basically, to ascertain about excavation models created from the description of a physical mean, from the rheology study, from the auscultation and from the numerical model. The fact of establishing a geomechanic model, that is a simplification of a real model, does not mean that we have to use the same conventional parameters of description, the same assays and the same points of instrumentation. A geomechanic model implies:

- Improving lab and in situ testes with the objective of obtaining data that are more reliable.

- Improving the instrumentation, being able to monitor closely and follow variations in the measurable quantities.

- Improving the geotechnical-structural mapping in a way to better represent 
the structures that condition the failure.

- Gathering all the data collect in a quantitative technique of calculus, allowing the analysis of the stresses and strains. (Validated model).

- Use of a valid model to simulate geometry and methodologies of excavations. The scheme of a calibrated model can be seen in Figure 1.

\section{Monitoring Conditions and Types}

The success of a monitoring program depends upon some keys factors discussed by [1]. With regard to the monitoring technique, few aspects should be emphasize: the objectives of the monitoring program; the equipment employed and how they are installed; the place chosen for installation; the frequency and time span of data recording; and the type and quality of the data obtained. Monitoring can be said to be qualitative, such as visual observation, or quantitative, when instrumentations are used to measure or estimate information directly (deformations, stress) or indirectly by indicators (acoustic emission, seismography, etc.).

\subsection{Sismo - Underground Excavation Monitoring System}

The underground excavation monitoring system (SISMO) [16] is a direct measuring mythology that aims to gather quantitative data of strain and estimated stress variation. It can be subdivided into three integrated parts:

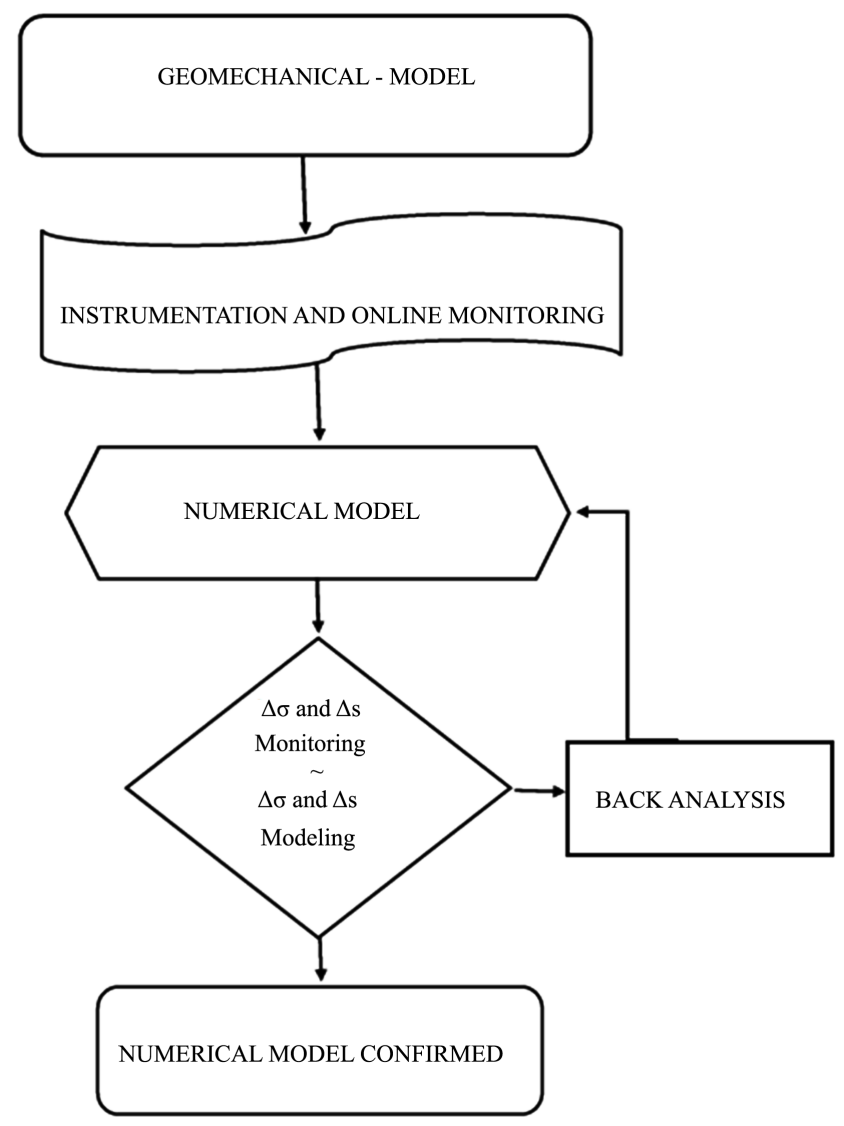

Figure 1. Schedule of explanatory model calibrated. 
- Convergence measurement component comprised of an encapsulated LVDT (Linear Variable Differential Transducer) sensor with real time transmitting capabilities. The LVDT can be coupled with telescopic rods, invar wire in single pairs or multiple points. Stress variation sensors similar to flat jacks of different shapes and sizes, to be installed inside pillars and excavation walls and PVT (Stress Variable Transducer) to be placed inside drill holes and natural discontinuities. Both systems are capable of real time data transmission

- Data acquisition Analogical to digital transducer board system utilizing from 6 to 12 channels. Each channel is used for one set of measurement, strain or stress variation.

\subsection{Data Processing Software}

A software called Estavel [16], was written in C++ to compile and to process the data received in any single channel or in simultaneously in all the 12 channels. Depending upon the arrangement of the measuring instruments it would be possible to work together with coupled strain/stress measurements of 12 different points. The data collect is then subjected to an initial statistical analysis by applying the Gradient Method [16].

\section{Monitoring and Modeling of a Calibrated Excavated Gallery}

Herein, this paper discusses a gallery dug into a massive dolomite. The main objectives of this study were:

- Monitoring Variations in stress and deformation in real time during the excavation with explosives;

- Feed the numerical model established with the software UDEC with the monitored data;

- Comparing the monitored data with data from numerical model calibrated.

\subsection{Geological Context of the Monitoring and the Place of Installation of the SISMO}

As shown in Figure 2, after the opening of a "stopping", a great collapse due to instability the walls took place. These walls are parallel to the areas of sub-vertical shear. The removal of ore from the instability of the walls of the stopping was done through a gallery-dug perpendicular to the shear zone vertical and sub-parallel to the shear zone of sub-horizontal. The gallery parallel to that was instrumented with the System of Monitoring SISMO. The depth of these galleries is $122 \mathrm{~m}$ and the concentrations of zinc ore from that mine, stay in areas of shear. These shear zones have the general direction of NE-SW stress of several kilometers thick and about $50 \mathrm{~m}$. It is reddish dolomite, shear and breccias, which separates the overlapping gray dolomite (cover - hanging wall) of dolomite roses (Lumpfish - footwall). A perpendicular gallery in the shear zones of the sub-vertical ore is horizontal. 


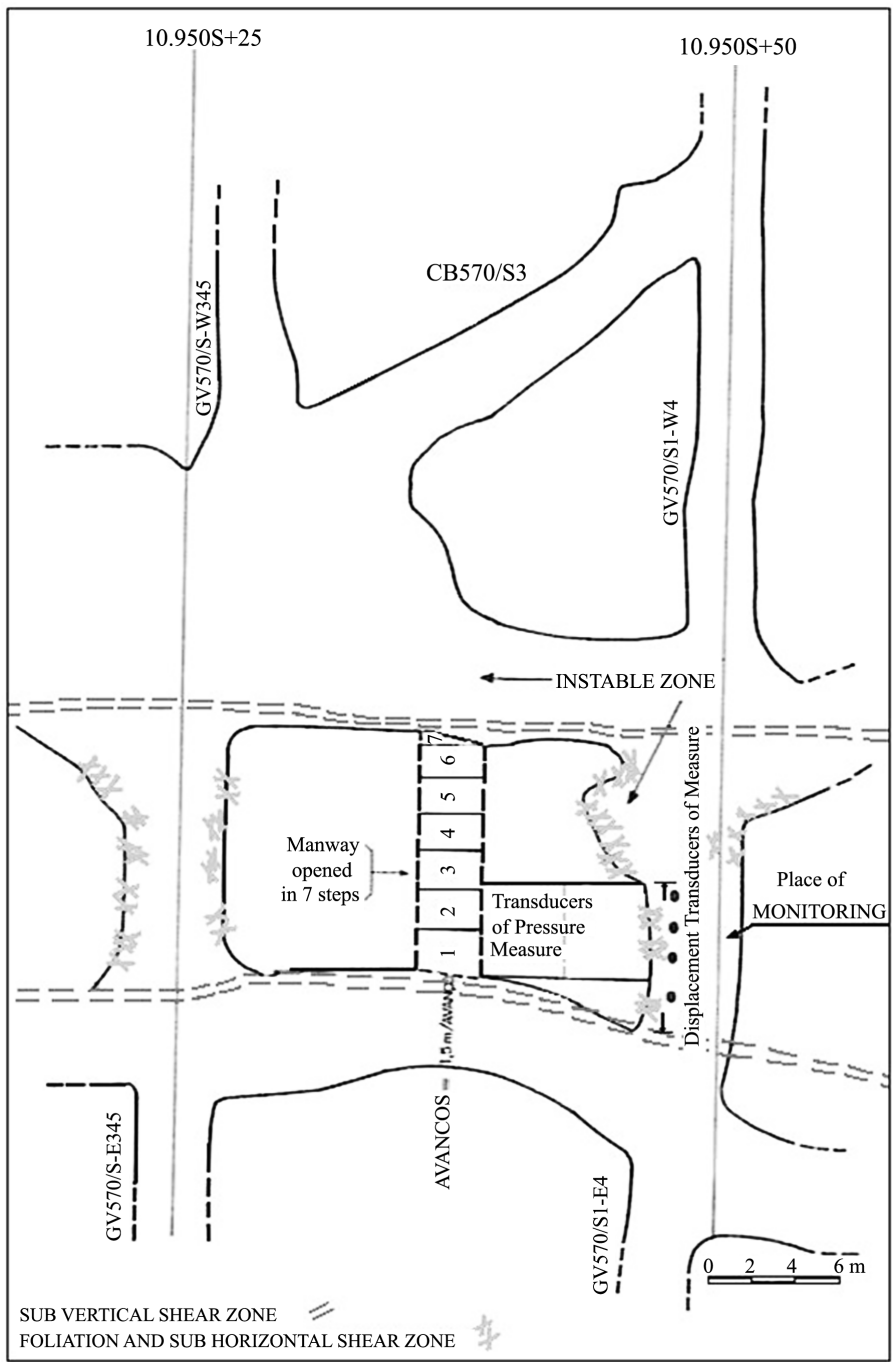

Figure 2. Floor plan of the site and the pillar where the SISMO was installed.

\subsection{Installation of the Instrumentation of the Sismo}

The gallery was instrumented with four FJ - Flat Jack - equipped with PVT Stress Variable Transducer and Transmit and 4 telescopic rods with LVDT. The wall of the gallery has been carefully mapped showing a mylonitic area close to the hole that holds the FJ numbers two and three. The FJ was installed at $3.5 \mathrm{~m}$ depth in hole of $75.54 \mathrm{~mm}$ in diameters, parallel to the attitude of the ore in place and $1.5 \mathrm{~m}$ perpendicular to the floor gallery. The walls of the gallery are 8 $\mathrm{m}$ thick (Figure 2). The sequence of installation and initial stress applied to each flat jack $\left(5 \mathrm{~kg} / \mathrm{cm}^{2}\right)$ allows monitoring the variation of stress in the $\mathrm{Y}$ direction, depending on the progress of the excavation front. The telescopic rods were installed near the center of the gallery ( $4 \mathrm{~m}$ wide by $3 \mathrm{~m}$ in height) according to the same sequence of pressure transducers. Use the terms convergence for displacement where the roof opens to the gallery and divergence for the reverse. Thus, the displacements and the variation of stress-floor ceiling were recorded before, during and after the passage of the front of excavation. The roof of the gallery 
has been carefully mapped giving families of discontinuities with a low dive angle. "Chinese hats" of steel covered the telescopic rods in order to protect them from falls cuttlefish that could occur during the opening of the gallery, and their attachment to the roof and floor of the gallery provided by manual drilling of shallow holes. The gallery was excavated a fire after seven advances to the same geometry. Each step was on average 1.5 meters.

\subsection{Results of Monitoring}

Monitoring during the SISMO application took place for 337.5 hours. The variation of stress $(\Delta \sigma)$ and deformation $(\Delta \gamma)$ (convergence) was recorded at constant intervals of 10 seconds. Figures 3-6 show the most relevant results. Initially treated by the method of moving averages to a constant sampling of 10 data recorded every second. This treatment helped prevent the spread of data.

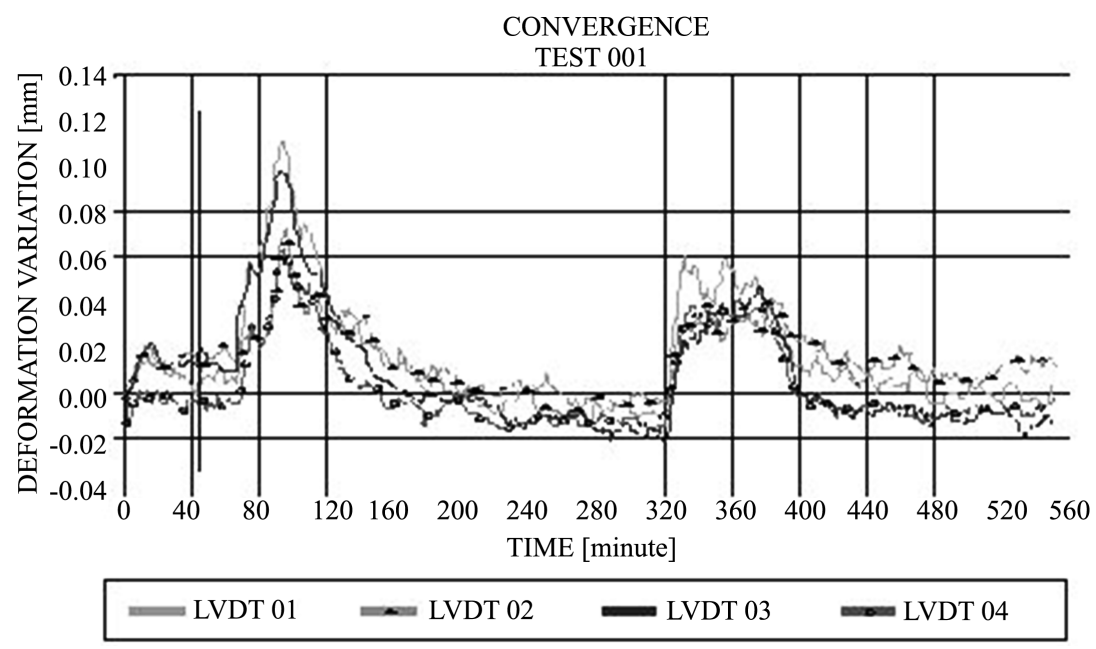

Figure 3. Test 001 - Variation in deformation.

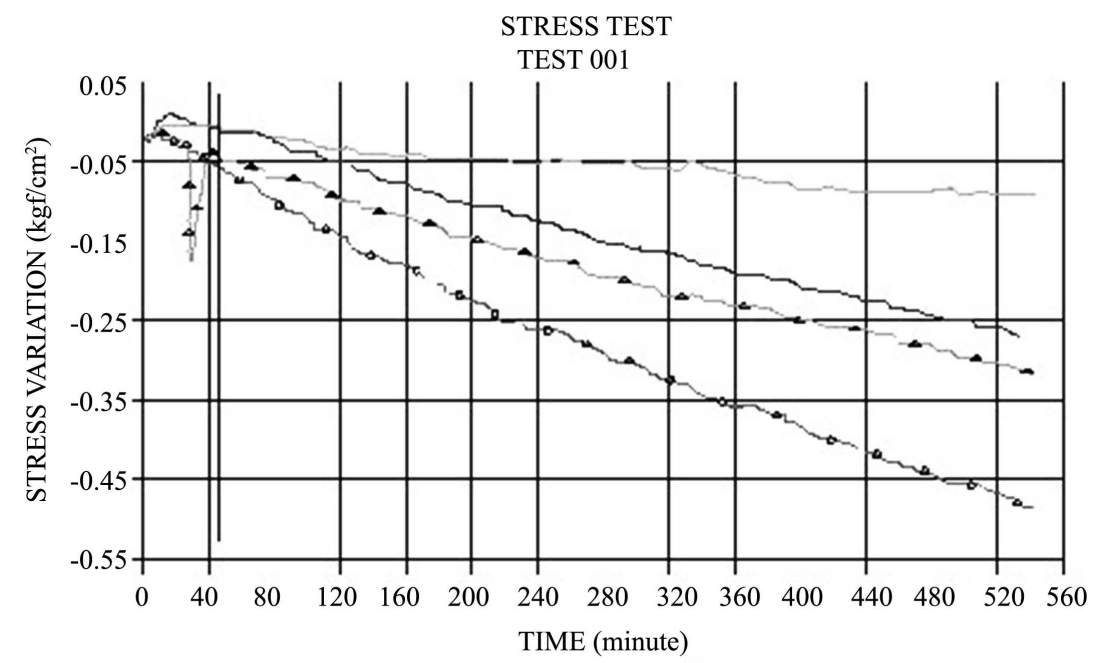

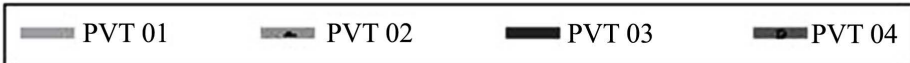

Figure 4. Test 001 - Variation in stress. 

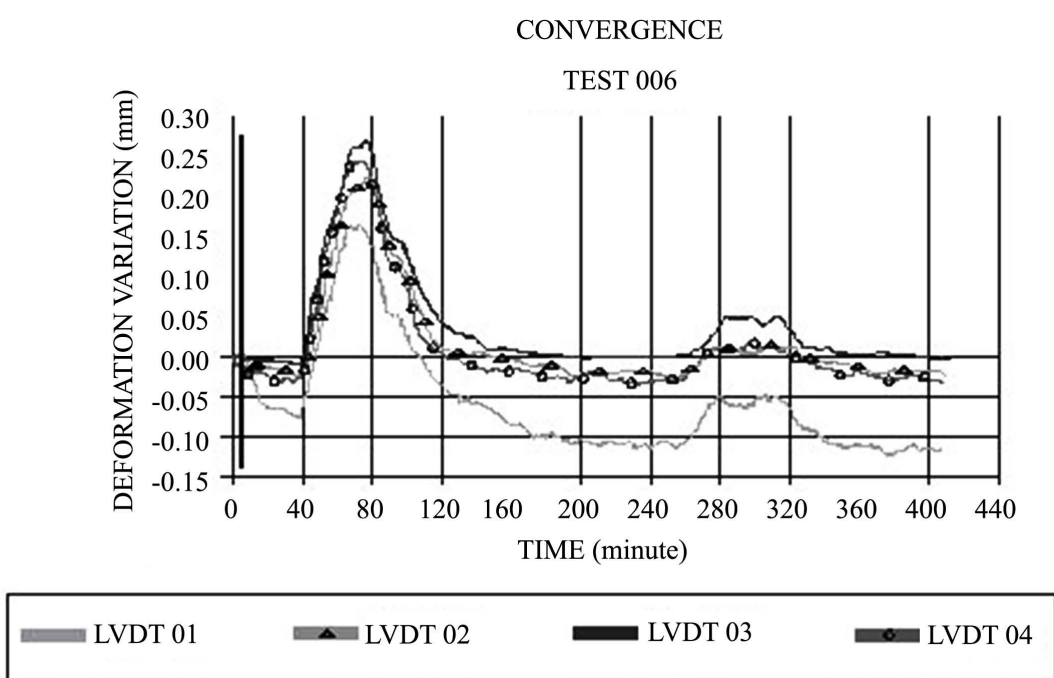

Figure 5. Test 006 - Variation in deformation.

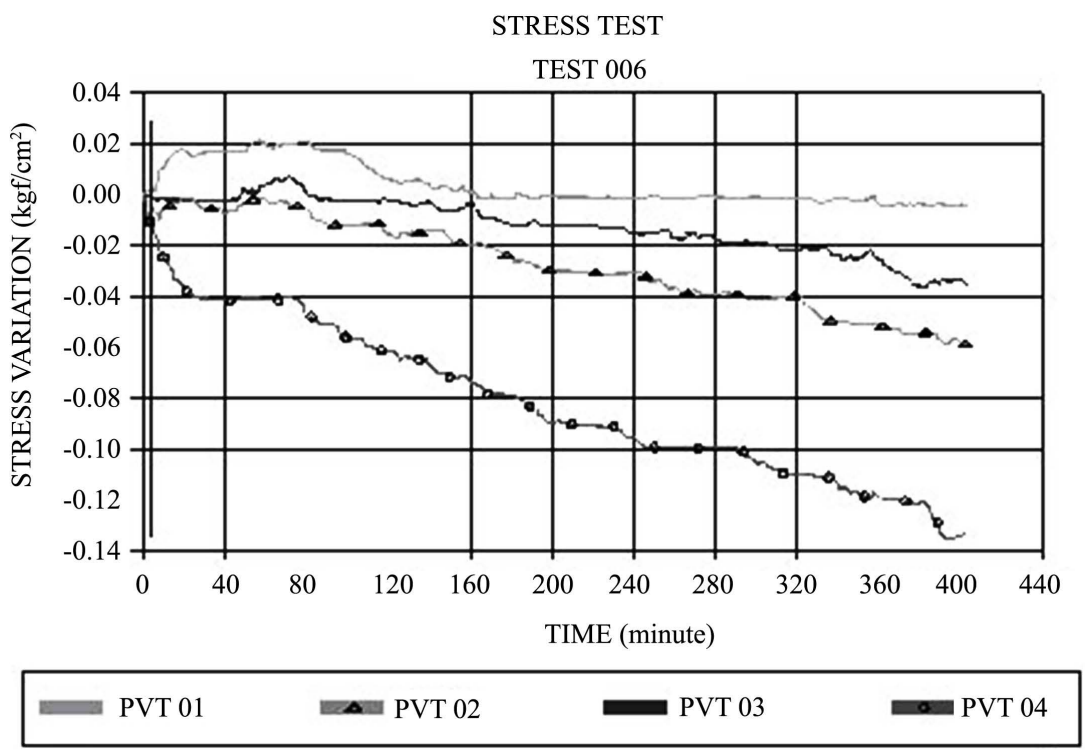

Figure 6. Test 006 - Variation in stress.

Test 001 - Figure 3 shows the results of variation in deformation with time $(\Delta \gamma)$ and Figure 4 shows the results of the variation of stress $(\Delta \sigma)$. In Figures 3-6, the vertical line shown next to 42 minutes highlights the moment of detonation. Before the excavation of small oscillations of the sensors indicate an average variation of $\Delta \gamma$ and $\Delta \sigma$ close to zero. The sensor stress PVTs 03 and 04 (Figure 4) showed greater relaxation of stress $\Delta \sigma$ before the test due to a small oil leak in the driver PVT 03, fixed in test 002. If $\Delta \gamma$, there is a delay between the detonation and the manifestation of increased convergence in the case $\Delta \sigma$, relaxation is immediate.

Test 006 - Figure 5 and Figure 6 respectively show $\Delta \gamma$ and $\Delta \sigma$. The progress of this test is $9.0 \mathrm{~m}$ and the remaining portion of the rock mass in the gallery damaged by fire and having a thickness of only $1.5 \mathrm{~m}$. Sensors LVDTs 03 and 04 
record the largest deformations. The sensor 04 records the PVT relaxation of the final portion of the massif belonging to the gallery. The influence of this final portion of the massive deformation of the sensors LVDTs 03 and 04 shows further convergence with respect to all other tests. However, the demonstration of convergence between 280 and 320 minutes is the lowest of all. Now that the ability of massive to the relaxation stress is significantly lower, sensors PVTs 01,02 and 03 were employed to register stress.

\subsection{Overview of the Tests}

Figure 7 and Figure 8 respectively show the convergence $(\Delta \gamma)$ and variation of stress $(\Delta \sigma)$ for all tests. It is observed that in the case of convergence, the time between 0 and 600 minutes (tests 001 and 002), the range of response from the

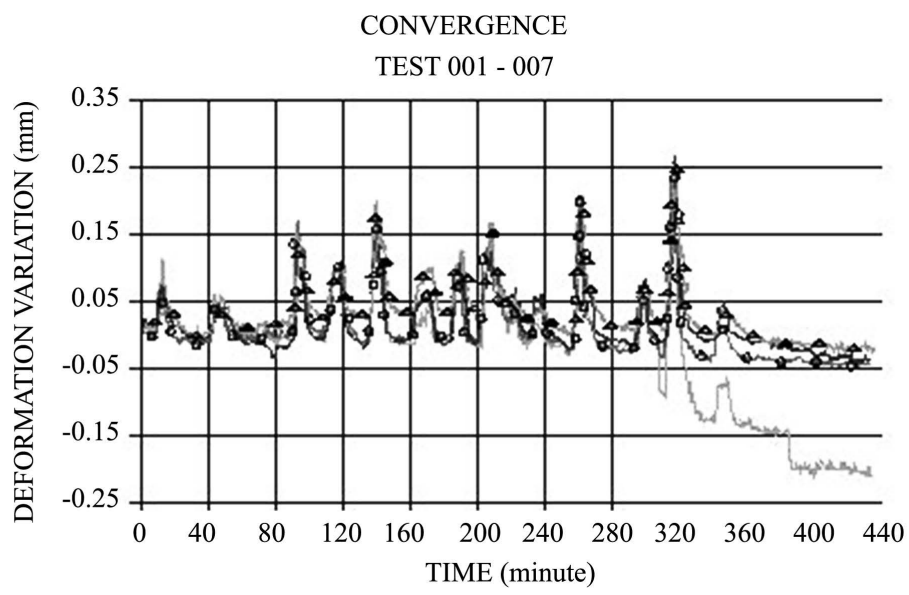
LVDT 01
LVDT 02
LVDT 03
$\therefore$ LVDT 04

Figure 7. All tests of variation in deformation.

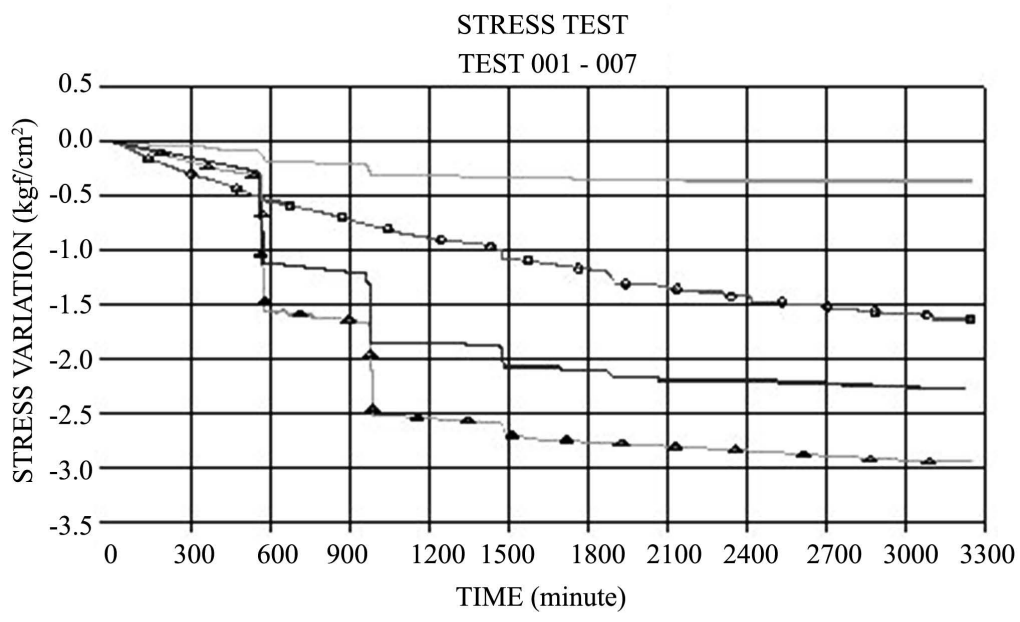

\#PT $01 \quad$ PVT $02 \quad$ PVT $03 \quad$ PVT 04

Figure 8. All tests of variation of stress. 
massive convergence is greater as the gallery progresses. Turning to the divergence stabilization and then end after took 3000 minutes. In the case of variation of the wall stress of the gallery excavated showed the relaxation of stress throughout the period of excavation, showing stronger relaxation PVTs the sensors 02 and 03 located in zone mylonilized. This area was found radial cracks and the water holes during the excavation. The variation of stress is stabilizing after 3000 minutes.

\subsection{Using the Program UDEC in the Analysis and Monitoring of the Excavation}

This program was used in two ways. The first directly in instrumentation where the model built was loaded with the speed of deformation obtained by displacement transducers in the roof and floor of the gallery. The second, the model was loaded with a gradient based on the specific weight of rocks. Both models have the same parameters needed for modeling, i.e. mechanical properties of rocks and joints. Figure 9 show the results for the first model. Because three-dimensional version is not used, the effect of relaxation was simulated with instantaneous opening of the gallery excavated in a plane perpendicular to the central section of the gallery. The test 006 Figure 4 and Figure 5 as used like model. Excavated in a plane perpendicular to the central section of the gallery. The test 006 Figure 4 and Figure 5 as used like model. After opening, the gallery instantly dug the model continued to be loaded simulating all phases of excavation. In Figure 9, you see that the joints open and close just after the excavation. Has a maximum closure of $2.66{ }^{*} 10^{-3} \mathrm{~m}$ (dark gray) and open joints (light gray) are zero normal force and stress. Note that there is a plastic zone together.

Job Title: Modelo CMM-SISMO - carregamento na borda interna From File:

$(* 10 * * 1)$

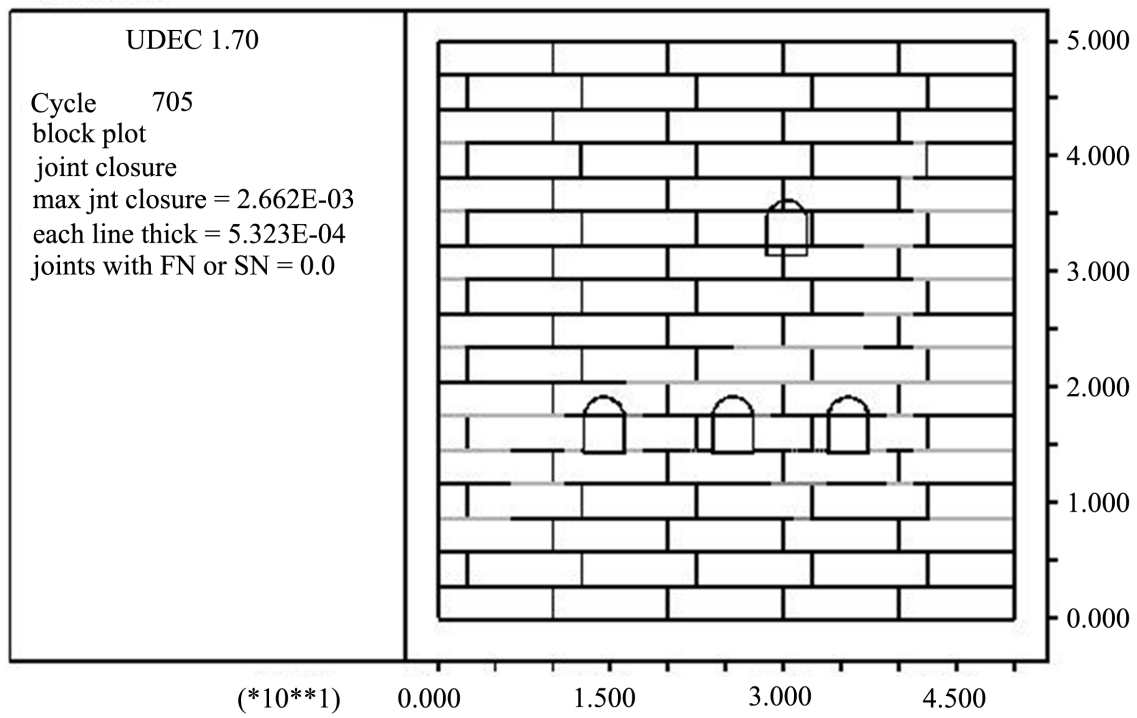

Figure 9. Vertical Section with model after opening. Open joints FN (Normal forces and $\mathrm{SN}$ Shears forces) =0.0 Mpa (light gray lines), closed joints $0.00266 \mathrm{~m}$ (dark gray lines). 


\section{Results}

The results in 006 test results were compared to the UDEC and the theoretical model of rheology behavior of the excavation. The curves obtained in the tests clearly show a visco-elastic behavior of the excavation, i.e., the deformation increases with time, "recovering" these deformations over time. This rheology model has the following theoretical formulation for the deformation behavior of $\mathrm{cm}$ function of time:

$$
\varepsilon=\sigma / E *\left(1-\mathrm{e}^{-t_{1} / t_{2}}\right)(\text { Kelvin MODEL })
$$

where: $\mathcal{E}$ strain, applied stress $\sigma, E$ modulus of elasticity, initial time $t_{1}$ and time $t_{2}$ end.

Data from the test 006 were treated statistically for comparison with the model of Kelvin. The outcome of treatment is shown below:

$$
\varepsilon=0.4159 * \mathrm{e}^{-0.04481 t}
$$

The constant $0.4159 \mathrm{~cm}$ and has a unit time (minutes) and correlation coefficient is 0.89 . Regarding the behavior of stress in time, the solid of Kelvin presents a model of relaxation of stress where the relaxation curves are very similar to those obtained in the tests. Figure 10 shows the result of a deformation of the test sensor 006 as compared with the Kelvin model and the models made with UDEC. It is observed that the Kelvin model is a good approximation to the actual test. The convergence curve obtained with the UDEC shows a good relationship with the actual test. This curve is referred to the loading on the roof and floor of the gallery. The curve relating the load from the distribution of the gradient, based on the specific weight of rocks similar to the function presents actual test, but with very discrepant values.

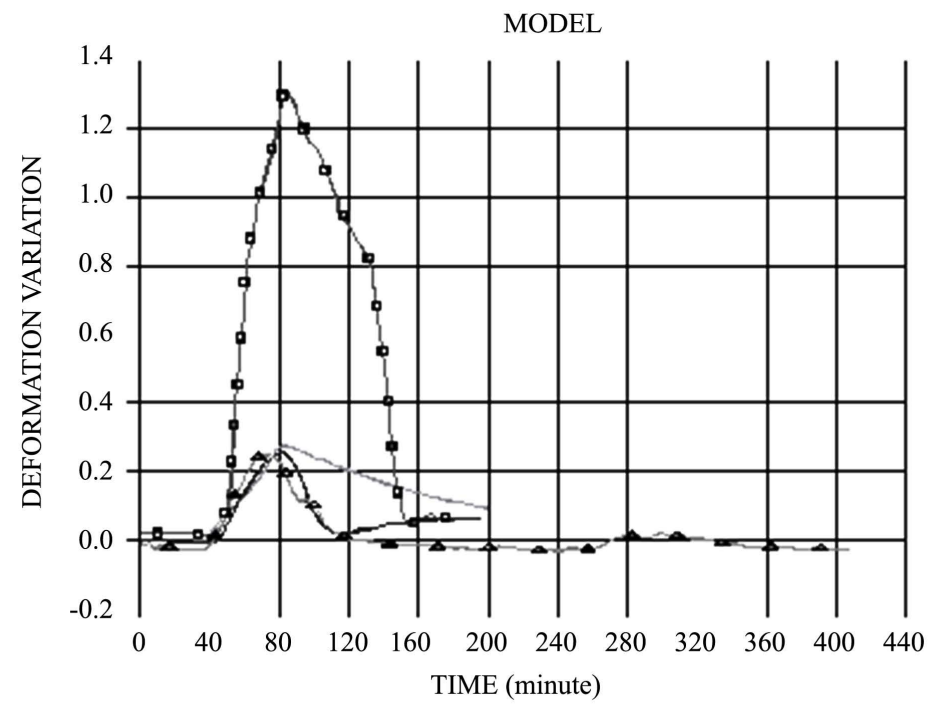

Model $(\mathrm{mm}) \quad \Delta$ Real Test $0.06(\mathrm{~mm})$

UDEC. Boin (cm) UDEC. Gray $(\mathrm{cm})$

Figure 10. Sensor of deformation of the test compared the 006 test and Kelvin models performed with UDEC. 
Figure 11 and Figure 12 show a comparison between, the two models loading and testing done in UDEC 006 all sensors. Figure 11 is on the convergence and Figure 12 the variation of stress. Observe that the model with loading on the roof and floor of the gallery, which used the velocities of deformations and stresses, fit the actual test.

The fact that the model of charging for the distribution of weight does not produce good results, has once again confirm that the relaxation of stress in this portion of the mass is favored by the shear zones. Otherwise, the gradient distribution of the column of rock in-situ is compatible with the deformation and

\section{DEFORMATION ANALYSES}

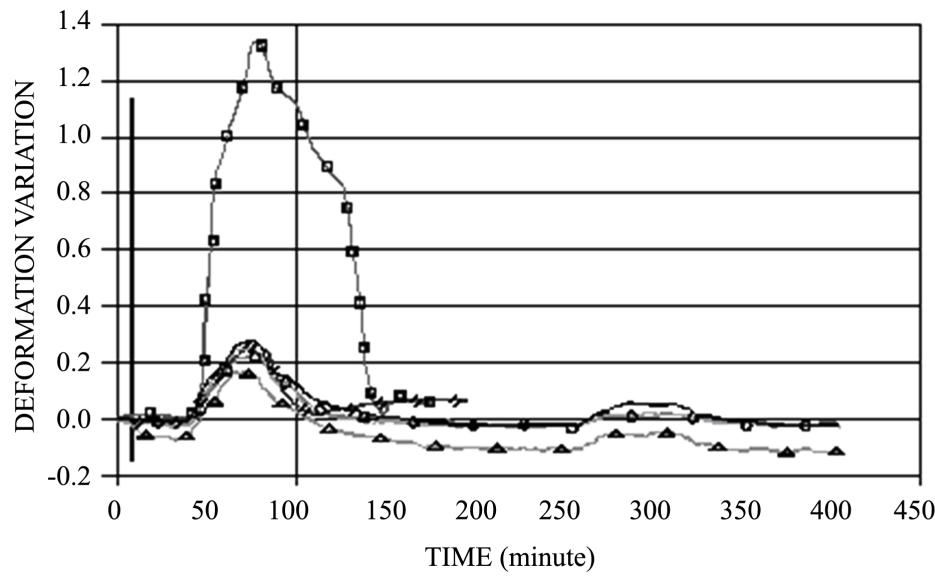

$\begin{array}{lll}\Delta \text { Real Test }(\mathrm{mm}) & \text { Real Test }(\mathrm{mm}) & \text { Real Test }(\mathrm{mm}) \\ \text { Real Test }(\mathrm{mm}) & \text { UDEC - Boin }(\mathrm{mm}) & \text { UDEC - Gray }(\mathrm{cm})\end{array}$

Figure 11. Comparative analysis of the variation of deformations.

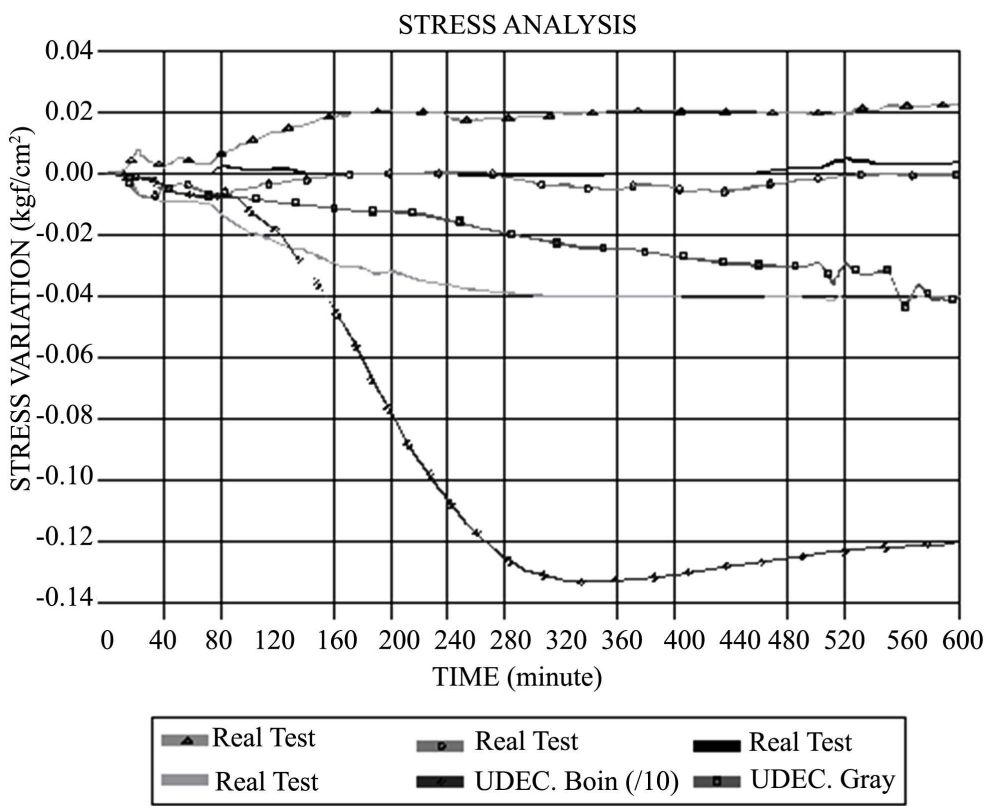

Figure 12. Comparative analysis of the variation of stress. 
relaxation of stress obtained in the tests. The horizontal joints open and close during the rise and fall of convergence and the establishment of zones of stressed turning into areas of stress, confirming a scheme of relaxation of stress at the site. Probably the site is the test of shear zones within past, this portion of the mass is favored by the relaxation of stress. It is interesting to note that beyond the zone of sub-vertical shear, the instability of the walls of excavations is striking; however, in the direction perpendicular to them, i.e. in the direction of excavation tools and models here, this instability is not in the size of the excavation.

\section{Conclusions}

The objective is to consider why you want to orchestrate and what is expected as a product of the monitoring, are factors that can ensure the success of the monitoring. The importance of choosing the site to be instrumented and the possible influences of geological structural features are essential for obtaining a good result. The calibrated model is a great tool for sound analysis of the mechanical behavior of solid excavated where you can learn to have a well-established and effective instrumentation.

The results confirm, at this stage of experience with the SISMO, the expectations with respect to their effectiveness and versatility in the acquisition and interpretation of data.

\section{Conflicts of Interest}

The author declares no conflicts of interest regarding the publication of this paper.

\section{References}

[1] Kaiser, K.P. (1995) Deformation Monitoring for Stability Assessment of Underground Openings. In: Rock Engineering: Comprehensive Rock Engineering, Vol. 4, Pergamon Press, Oxford, 607-629.

[2] Deb, D. (2006) Finite Element Method FEM. Prentice Hall of India Pvt. Ltd., New Delhi.

[3] Cundall, P.A. (1980) A Generalized Distinct Elements Program for Modelling Jointed Rock-Final Technical Report. European Research Office, US Army.

[4] Katsikadelis, J. (2016) The Boundary Element Method for Engineers and Scientist. 2nd Edition, Elsevier, Amsterdam. https://doi.org/10.1016/B978-0-12-804493-3.00005-9

[5] Lemos, J.A.S.V. (1987) A Distinct Element Model for Dynamics Analysis of Jointed Rock with Applications to Dam Foundations and Fault Motion. PhD Thesis, University of Minnesota, Minneapolis.

[6] Cundall, P.A. (1971) A Computer Model for Progressive Simulating Large-Scale Movements in Blocky Rock Systems. Proc. Symp. Int. Soc. Rock Mech., Nancy, Vol. $1,11-18$.

[7] Haimson, B.C. (1978) The Hydrofracturing Stress Method and Recent Field Results. International Journal of Rock Mechanics and Mining Sciences \& Geomechanics 
Abstracts, 15, 167-178. https://doi.org/10.1016/0148-9062(78)91223-8

[8] Yoshiaki, M. (1995) Predictive Calculation and Monitoring of Rock Stress and Displacement Induced by Ore Extraction. In: Comprehensive Rock Engineering, Vol. 4, Pergamon Press, Oxford, 653-669.

https://doi.org/10.1016/B978-0-08-042067-7.50030-1

[9] Serata, S. (1988) Integration of Field Instrumentation and Computer Simulation: Development and Application of the SPDR Method. Field Measurements in Geomechanics. Proceedings of the 2nd International Symposium on Field Measurements in Geomechanics, Kobe, 212-228.

[10] Sakurai (1995) Back Analysis in Rock Engineering. In: Comprehensive Rock Engineering, Vol. 4, Pergamon Press, Oxford, 543-569.

https://doi.org/10.1016/B978-0-08-042067-7.50026-X

[11] Gama, E.M. (1993) System of Monitoring Underground Excavation. SISMO 1 th of South American Symposium Rock Mechanics, 123, 145.

[12] Kaiser, K.P. (1987) Detection of Rock Mass Ruptures Modes. Proc. 6th Int. Cong. Rock Mech., Vol. 3, 1457-1461.

[13] Kaiser and Korpach (1987) Use of Stress Variation Measurements to Access Performance of Underground Excavation. Prediction and Performance in Geotechnical Engineering, Calgary, 319-328.

[14] Pelli, F. (1987) Near Face Behavior of Deep Tunnels. PhD Thesis, University of Alberta, Edmonton.

[15] Sakurai, S. (1983) Displacement Measurements Associated with the Design of Underground Openings. Proc. Int. Sympo. Field Measurements in Geomechanics, Zurich, 1163-1178.

[16] Gama, E.M. (2016) Patent PI 020332210-4 Instituto Brasileiro de Patentes-INPI. 